\title{
In vivo intratumor angiogenic treatment effects during taxane-based neoadjuvant chemotherapy of ovarian cancer
}

\author{
Martin Pölcher*1, Christian Rudlowski1, Nicolaus Friedrichs²,4, Marieke Mielich', Tobias Höller³, Mathias Wolfgarten', \\ Kirsten Kübler', Reinhard Büttner², Walther Kuhn' and Michael Braun'
}

\begin{abstract}
Background: The aim of our study was to analyze the effect of taxane-based chemotherapy on tumor angiogenesis in patients with advanced epithelial ovarian cancer.

Methods: Within a prospective phase II trial, 32 patients with stage IIIC and IV ovarian cancer were treated with either two or three cycles of neoadjuvant chemotherapy prior to cytoreductive surgery. Carboplatin (AUC5) and docetaxel $\left(75 \mathrm{mg} / \mathrm{m}^{2}\right)$ were administered intravenously in a 3-weekly schedule. Changes in intratumor microvessel density (MVD) were assessed with immunohistochemistry by staining pre- and posttreatment surgical tumor specimens with panendothelial, neovascular and lymphatic vessel markers.

Results: Mean values of MVD defined by CD31, CD34, CD105 and D2-40 antibodies showed 12.3, 21.0, 2.7 and 3.1 vessels per high power field (HPF) before chemotherapy and increased after treatment to 15.3, 21.8, 4.8 and 3.6 per HPF, respectively. These changes were significant for CD31 $(p=0.04)$ and for CD105 $(p=0.02)$.

Conclusion: Taxane-based chemotherapy appears to promote tumor vascularization when administered every 3 weeks. A possible explanation is the secondary recovery of MVD in response to immediate cytotoxic and antiangiogenic effects of the chemotherapy. If confirmed prospectively, these findings favor shorter treatment intervals of taxane-based chemotherapy to counteract proangiogenic recovery.
\end{abstract}

\section{Background}

Although about $80 \%$ of advanced ovarian cancer patients respond well to standard management - primary cytoreductive surgery followed by platinum/taxane-based chemotherapy - the majority of patients develop recurrent disease and die of progressive disease[1]. Therefore changes in therapeutic procedures are of clinical interest.

The application of neoadjuvant chemotherapy in advanced ovarian cancer is the subject of past and recent study efforts [2-4]. Results of a recently reported phase 3 study with 704 patients enrolled and a treatment schedule with 3 cycles carboplatin/paclitaxel preoperatively demonstrated that neoadjuvant chemotherapy produces similar PFS and OS rates compared to standard primary

\footnotetext{
*Correspondence: martin.poelcher@ukb.uni-bonn.de

1 Department of Gynecology and Obstetrics, Center for Integrated Oncology, Bonn University Medical Center, Germany

Full list of author information is available at the end of the article
}

cytoreductive surgery and provides a significantly lower perioperative morbidity and mortality in the group treated with neoadjuvant chemotherapy [5].

Preoperative chemotherapy provides an excellent opportunity to analyze cytotoxic therapy effects on the tumor microenvironment; an area of research which received little consideration in the literature so far. Malignant tumors are regarded as complex tissues in which genetically altered malignant cells interact with several normal cell types that collaborate and support malignant growth [6] Based on the impact of neovascularization which contributes to the growth of a tumor mass and the formation of metastases, great efforts have been undertaken to develop therapeutic tools to target this process [7].

Intratumor microvessel density (MVD) has been used to examine the role of vascularization within the malignant process. High MVD is associated with parameters of 
tumor aggressiveness such as greater incidence of metastases and decreased survival [8]. It was found to have independent prognostic significance when compared with traditional prognostic markers by multivariate analysis in many types of cancer. While the prognostic impact of high MVD In ovarian cancer patients was demonstrated in numerous retrospective studies [9-14], other studies failed to prove a significant association [15-17].

CD31, a transmembrane glycoprotein found at the intercellular junctions of endothelial cells and CD34, a surface glycoprotein of unknown function serve as panendothelial markers, whereas CD105 (endoglin) is expressed almost exclusively on proliferating endothelial cells that are induced by tumoral factors for neoangiogenesis [18-20]. D2-40, a monoclonal antibody, specifically recognises podoplanin and is the most sensitive and specific antibody for the detection of lymphatic endothelium [21].

Anticancer chemotherapeutic agents are known to directly inhibit tumor cell proliferation. In addition, chemotherapeutic drugs were reported to have antiangiogenic activity [22].

The aim of our study was to assess the chemotherapeutic effect on angiogenesis by comparing tumor vasculature before and after neoadjuvant chemotherapy in ovarian cancer patients.

\section{Methods}

Between February 2003 through March 2008, patients with advanced stage IIIC and IV ovarian cancer and large volume ascites $(>500 \mathrm{~mL})$ were treated with neoadjuvant chemotherapy as part of a multicenter prospective randomized phase 2 trial [23]. This trial was planned to evaluate response to neoadjuvant chemotherapy, and to analyze surgical outcome. Treatment consisted of either two or three of six cycles of intravenous carboplatin (area under the curve 5) and $75 \mathrm{mg} / \mathrm{m}^{2}$ of docetaxel at 21-day intervals before cytoreductive surgery in order to find a suitable regimen for a planned phase 3 trial. All patients were regularly followed up at 3-month intervals for the first two years and at 6-month intervals thereafter.

To confirm the diagnosis laparoscopic biopsy was performed before chemotherapy and tumor samples were taken from the ovary and/or the peritoneum of the abdominal wall. Cytoreductive surgery was performed within four weeks of the last scheduled chemotherapy cycle and tumor tissue was excised at the beginning of cytoreductive surgical procedures. If no macroscopic residual tumor was detectable at the ovary and/or the peritoneum of the abdominal wall, any macroscopic tumor tissue was obtained irrespective of the anatomic site.

This is a single institution analysis. Of 93 patients enrolled in the multicenter study, 43 patients were treated at the University of Bonn Medical Center and form the basis of our analysis. Tissue sampling and documentation was performed in a standardized fashion. Of the 43 patients, in 32 cases, paired tissue samples from laparoscopy and laparotomy were assessable for the evaluation of MVD before and after treatment.

None of the patients received erythropoetin stimulating agents before cytoreductive surgery. The protocol was approved by the institutional review board. All patients gave written informed consent.

\section{Immunohistochemistry}

Original hematoxylin and eosin stained slides were reviewed by a board certified pathologist (N.F.). Corresponding tumor blocks were obtained. Formalin-fixed tissue specimens were embedded in paraffin and $2 \mu \mathrm{m}$ sections were dried overnight at room temperature, deparaffinized and rehydrated by decreasing concentrations of ethanol followed by incubation in Tris buffer. For antigen retrieval, the sections were microwaved twice for $15 \mathrm{~min}$ at $600 \mathrm{~W}$ in $10 \mathrm{mM}$ citrate buffer, $\mathrm{pH}$ 6. The following steps were performed semiautomatically using a streptavidin-biotin-peroxidase technique and a DAKO TechMate $^{\mathrm{TM}} 500$ following the instructions of the provider (Dako, Hamburg, Germany). Positive control experiments were performed using tissue slides with microvessels and negative controls by substituting the primary antibody by non-specific immunoglobulin. All specimens were stained within the same pass.

The following primary antibodies were used for immunohistochemical detection: anti-human CD 31 (Clone JG 70 A, 1:100; DAKO), anti-human CD34 (Clone QBEnd10, 1:100; DAKO), anti CD 105 (Clone SN6 h, 1:50; DAKO) and anti-human D2-40 (Clone D2-40, 1:50; Signet, Dedham, MA, USA).

MVD was measured as reported by Weidner et al. [24]. Using a light microscope, an experienced blinded investigator screened with a $40 \times$ magnification for a single area of invasive tumor representative of the highest microvessel density (neovascular "hotspot"). Hotspots were defined as the area of greatest vasculature within the tumor epithelium and immediate adjacent stroma. Areas of stroma without tumor cells were not considered. Vessels with muscular walls were excluded. The number of positively stained vessels was counted in 3 high power fields $\left(200 \times\right.$ or $\left.0.74 \mathrm{~mm}^{2}\right)$ in each tissue sample and the average value was used as a basis for calculating.

\section{Statistical analysis}

Statistical analysis was performed using the software SAS 9.1.3 (SAS Institute Inc. Cary, NC, USA) and included non-parametric group comparison tests (Mann-Whitney and Wilcoxon-test) nonparametric (Spearman) correlation tests, and parametric (Cox proportional) and non- 
parametric (Kaplan-Meier) survival analysis with $\mathrm{p}<0.05$ considered significant.

\section{Results}

The clinical and histological characteristics of the patients included in this study are summarized in Table 1. Ascites volume, target lesions and CA 125 serum levels were compared to pretreatment findings before cytoreductive surgery. All patients responded to the initial preoperative treatment.

For each marker, pre- and posttreatment specimens of 32 patients were analyzed. In three cases the pretreatment specimens showed severe artefacts, which prevented their use for the designated analyses due to poor quality. Pre- and posttreatment values were excluded pairwise in these cases.

The highest vessel counts were found by immunostaining with anti-CD34 antibody. There was a strong correlation between both panendothelial markers CD34 and CD31 (Spearman-Rho correlation coefficient 0.67, significance $<0.01)$. By comparison, the selective staining of CD105 (neovascularisation) and D2-40 (lymphatic vessels) generated clearly lower values of MVD (Figure 1).

Changes from pre- to posttreatment MVD are shown in Figure 2. CD31 and CD105 values showed a significant increase after treatment $(\mathrm{p}=0.04$ and $\mathrm{p}=0.016)$. There was no significant difference in the mean changes of all MVD markers between two and three cycles of treatment (data not shown). Changes of MVD markers (CD31, CD34 and CD105) were not associated with grade or residual tumor after surgery and further, changes of the lymphatic vessel marker D2-40 were not associated with nodal involvement, grade or residual tumor after surgery.

Mean follow up was 24 months (7 to 65 months), median progression-free survival (PFS) was 13.3 months (95\% Confidence Interval (CI) 10.9 to 15.7) and median overall survival (OS) was 36.0 (95\% CI 15.9 to 56.0) months. After dichotomization at the median into groups expressing high or low levels of CD31, CD34, CD 105 and D2-40 no significant differences were predictable in the univariate analyses for PFS and OS in both, pretreatment and posttreatment values. The same applies to comparing patients with increasing or decreasing levels of MVD after therapy.

Representative images of the microvessel immunostainings are shown in Figure 3.

\section{Discussion}

While chemotherapy has been reported to target endothelial cells in blood capillaries, this study demonstrates that taxane-based neoadjuvant chemotherapy in ovarian cancer does not exert antiangiogenic treatment effects in residual tumor foci.
Table 1: Patient characteristics

\begin{tabular}{|c|c|}
\hline & $\mathbf{N}$ \\
\hline Number of patients & 32 \\
\hline \multicolumn{2}{|l|}{ Age -- (y) } \\
\hline Median & 60 \\
\hline Range & $34-78$ \\
\hline \multicolumn{2}{|l|}{ Histological type } \\
\hline serous/serous-papillary & 31 \\
\hline Endometrioid & 1 \\
\hline \multicolumn{2}{|l|}{ Histological grade } \\
\hline G 2 & 12 \\
\hline G 3 & 20 \\
\hline \multicolumn{2}{|l|}{ Stage } \\
\hline IIIC & 30 \\
\hline IV & 2 \\
\hline \multicolumn{2}{|l|}{ CA $125(\mathrm{U} / \mathrm{mL})$} \\
\hline Median & 1376 \\
\hline Range & $(86-9030)$ \\
\hline \multicolumn{2}{|l|}{$\begin{array}{l}\mathrm{CA} 125(\mathrm{U} / \mathrm{mL}) \text { after } \\
\text { preoperative treatment }\end{array}$} \\
\hline Median & 71 \\
\hline Range & $(17-2794)$ \\
\hline \multicolumn{2}{|l|}{$\begin{array}{l}\text { Number of chemotherapy } \\
\text { cylcles before cytoreductive } \\
\text { surgery }\end{array}$} \\
\hline Two & 19 \\
\hline Three & 13 \\
\hline \multicolumn{2}{|l|}{$\begin{array}{l}\text { Residual disease after } \\
\text { cytoreductive surgery }\end{array}$} \\
\hline no gross residual disease & 9 \\
\hline$\leq 1 \mathrm{~cm}$ & 19 \\
\hline$>1 \mathrm{~cm}$ & 4 \\
\hline \multicolumn{2}{|l|}{ Lymph node status } \\
\hline NO* & 13 \\
\hline N1 & 7 \\
\hline NX & 12 \\
\hline \multicolumn{2}{|l|}{ Recurrence status (\%) } \\
\hline recurrent disease & 21 \\
\hline Dead & 17 \\
\hline
\end{tabular}

*at least 25 lymph nodes 


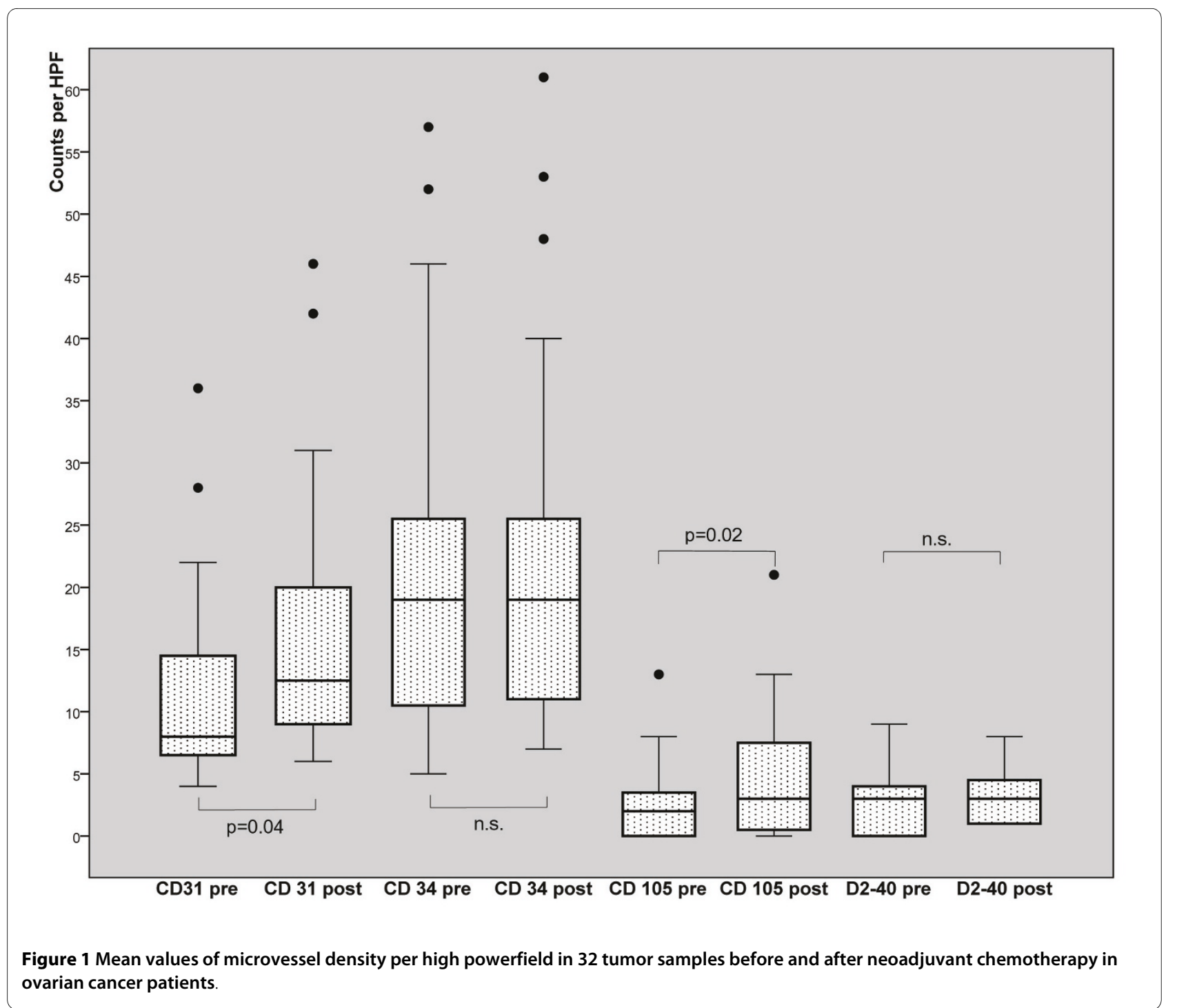

Although endothelial cells are assumed to be genetically stable and have a low mutation rate, antineoplastic cytotoxic agents are regarded as inhibitors of angiogenesis [25]. Taxanes are microtubule-stabilizing drugs and inhibit endothelial cell proliferation and tubule formation in vitro [26,27]. Docetaxel, which is the study medication of this trial, appears to be more potent at inhibiting angiogenesis in vitro and in vivo than paclitaxel [28], which is the standard medication for treatment of advanced ovarian cancer patients. Furthermore, antiangiogenic activity is not only thought to be mediated by direct effects on endothelial cells but it is also thought to be mediated through effects on cancer cells. Killing cancer cells and eliminating critical cell survival or proangiogenic factors (e.g. vascular endothelial growth factor), also affects the endothelial cell compartment and causes antiangiogenic activity [29]. Therefore, comparing tumor samples taken before and after neoadjuvant che- motherapy, one would expect to find a reduction of microvessel density (MVD) in the posttreatment specimens by an inhibition of tumor angiogenesis.

However, in the current analysis all vessel markers showed increasing mean levels after treatment, indicating a lack of a relevant antiangiogenic treatment effect.

CD105 has been considered as a specific and sensitive marker to detect newly sprouting vessels [19]. In twothirds of the tumor specimens posttreatment samples showed an increased number of CD105 positive vessels as a sign of newly generated vessels. Lymph vessels however, visualized by D2-40 did not show changes in the tumor environment. An inhibitory effect of chemotherapy or, inversely, an increase of the lymph vessel density due to a proangiogenic effect was not found in this study.

Tumor and host-mediated pathways might inverse antiangiogenic treatment effects. There is a growing body of evidence suggesting that circulating bone marrow 
A

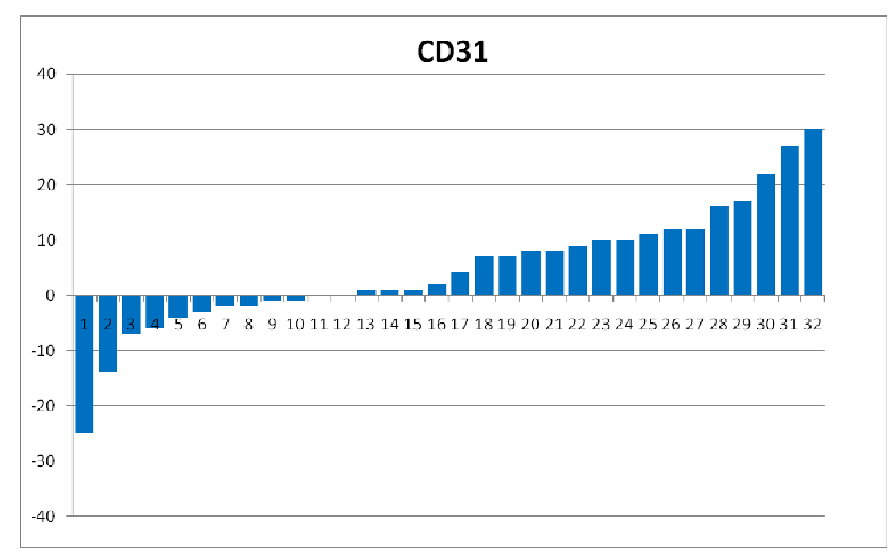

B

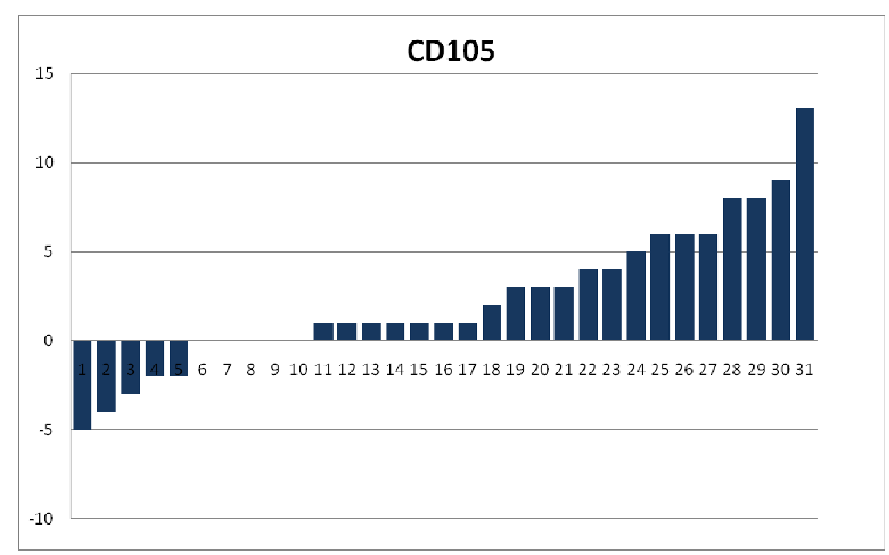

C

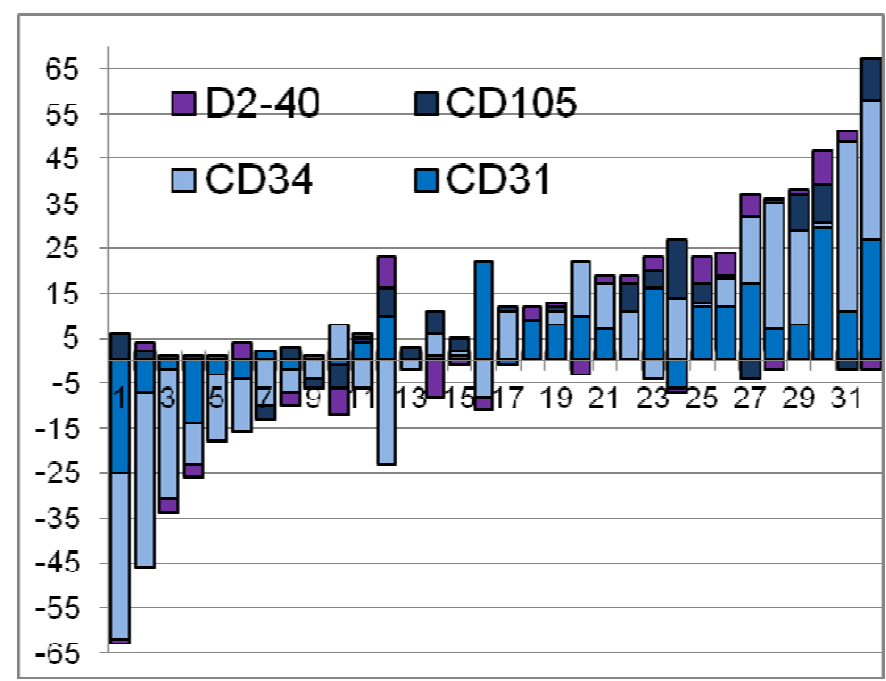

Figure $\mathbf{2}$ Changes of microvessel density per high powerfield in $\mathbf{3 2}$ tumor samples after chemotherapy treatment. Waterfall plots for (A) panendothelial (CD31) and (B) selective endothelial markers (CD105); (C) joint illustration of all markers. 


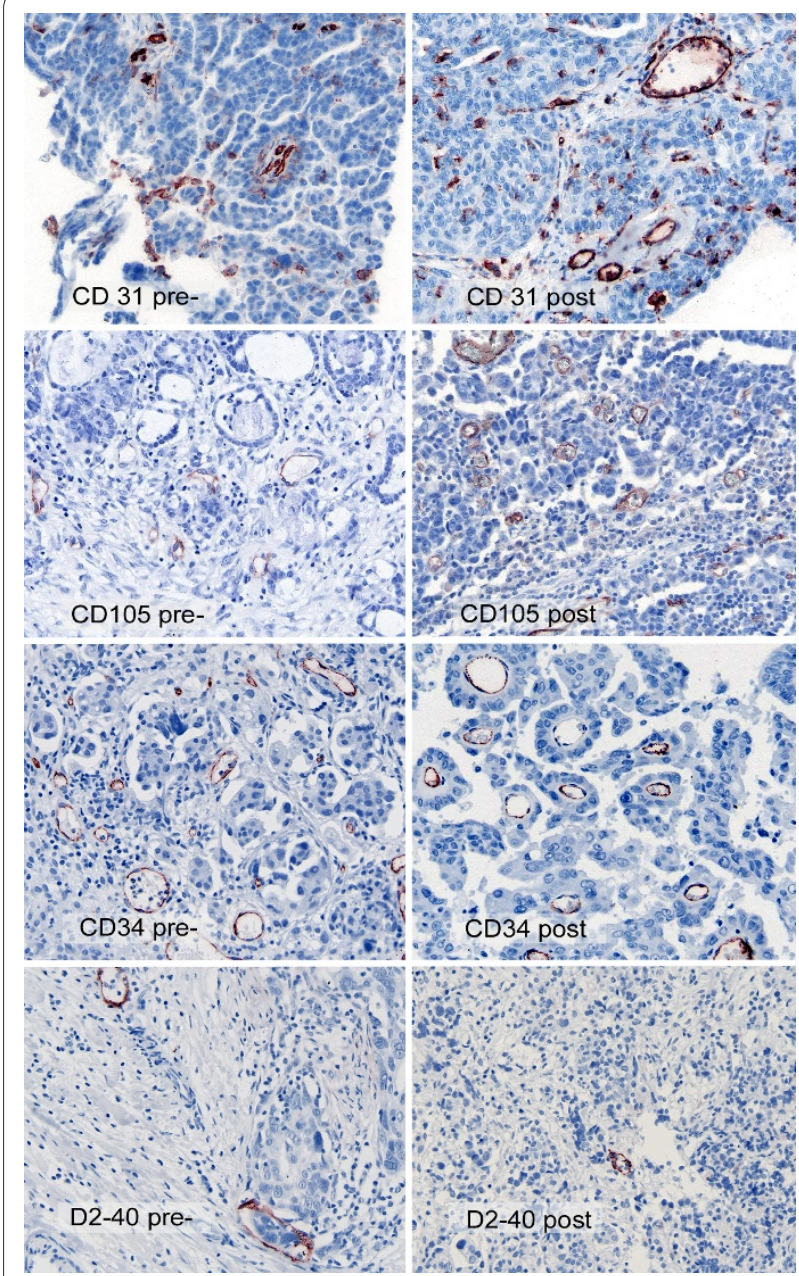

Figure 3 Representative images of the immunostaining showing antigen expression in pre- and posttreatment samples of patients treated with neoadjuvant chemotherapy.

derived endothelial progenitor cells (CEP) are able to support the vascularization of tumors and may therefore play a synergistic role with angiogenesis [30]. Tumor vasculature does not necessarily derive from endothelial cell sprouting, but CEP home to sites of neovascularization and differentiate into endothelial cells [31]. Recent data demonstrates that some chemotherapeutic drugs can cause simultaneously host-mediated counterregulatory responses from the bone-marrow resulting in tumor angiogenesis and vasculogenesis [32]. This mobilization effect in CEP levels may facilitate tumor cell repopulation during the common time intervals between the individual chemotherapy cycles [33].

Chemotherapy is optimally given at a maximum tolerated dose, with off-therapy intervals of 3 weeks to rescue bone marrow and intestine. Antiangiogenic therapy requires that endothelial cells be exposed to steady blood levels of the inhibitor [34]. Most recent investigations on the antiangiogenic efficacy of different application schedules suggested the use of a tightly spaced, continuous application of appropriate anticancer chemotherapeutic agents $[35,36]$. These application schedules are able to exert a strong antiangiogenic effect as indicated by an increase of apoptosis of tumor endothelial cells [37]. Furthermore, the mobilization of CEP is decreased in these schedules [33,38]. It has been hypothesized that a more frequent administration of paclitaxel exhibits proapoptotic and antiangiogenic properties and therefore increases its antineoplastic effect $[39,40]$.

A phase 3 trial (JGOG3016) with 637 advanced ovarian cancer patients enrolled compared a dosedense weekly paclitaxel regimen (Carboplatin AUC 6 q21d and Paclitaxel $\left.80 \mathrm{mg} / \mathrm{m}^{2} \mathrm{~d} 1,8,15, \times 6-9\right)$ with standard treatment (Carboplatin AUC 6 and Paclitaxel $180 \mathrm{mg} / \mathrm{m}^{2} \mathrm{q} 21 \times 6-9$ ) after cytoreductive surgery [41]. This study demonstrated a significant improvement of PFS in the arm with weekly taxane (28 vs.17 months; $\mathrm{p}=0.02$ ) and a significant improvement in the overall survival rate after 3 -years (72 vs. $65 \% ; p=0.03)$. Increased doses of paclitaxel of 200 $\mathrm{mg} / \mathrm{m}^{2}, 225 \mathrm{mg} / \mathrm{m}^{2}$ or $250 \mathrm{mg} / \mathrm{m}^{2}$ given every 3 weeks have not shown a benefit in survival rates compared to standard dosage $\left(175 \mathrm{mg} / \mathrm{m}^{2}\right)$ [42-44]. The authors concluded that higher survival rates without improved response rates in this study might be attributed to an additional antiangiogenic effect of the weekly application of paclitaxel.

We are aware of several limitations in our experimental approach. Laparoscopic biopsies are mostly smaller than tumor specimens after cytoreductive surgery and may have fewer vascular "hotspots". Therefore initial MVD may be underestimated. We tried to avoid paired sampling from different sites at the pre- and posttreatment surgical procedures, but this was not always feasible due to tumor response after neoadjuvant chemotherapy. However, the immunohistochemistry analysis is based on exclusively pathologically confirmed vital tumor tissue. Therefore, significant differences in MVD derived from different sites are possible but unlikely.

Inflammatory cells, namely monocytes, macrophages, $\mathrm{T}$ lymphocytes and neutrophils, fully participate in the angiogenic process by secreting cytokines that may affect endothelial cell functions, including proliferation, migration and activation. Therefore, MVD might also be affected by an immune response to tumor cell damage. The timing of surgery after the preoperative regimen may be crucial, at least with respect to the expression of these MVD markers. All patients included in this study underwent cytoreductive surgery at least after 21 days and within 35 days after the completion of preoperative chemotherapy. The long drug-free periods might provide time for endothelial cells to repopulate the damaged tis- 
sues, thereby reducing an antiangiogenic effects of these drugs [45].

Neither pretreatment MVD nor MVD changes after chemotherapy examined here were associated with survival. However, the limited sample size and the inclusion of patients with unfavorable prognostic markers (ascites, stage IIIC and IV) decrease the ability to demonstrate any effect on survival.

Specific antiangiogenic therapy targeting the vascular epithelial growth factor (VEGF) - pathway has found its way into clinical trials and first results show promise for this approach in ovarian cancer treatment $[46,47]$. Many unanswered questions remain to be clarified. It is not clear whether combination or concurrent antiangiogenic therapy is more sufficient or whether maintenance treatment should be pursued. Recently, converse treatment effects were reported as antiangiogenic therapy elicited malignant progression in animal trials $[48,49]$.

Our data indicates that neoadjuvant chemotherapy provides an excellent opportunity to in vivo assess changes in the tumor environment by comparing preand posttreatment samples. This may be helpful to identify treatment effects of cytotoxic drugs.

\section{Conclusion}

These findings suggest that in addition to the cytotoxic effect, the taxane-based chemotherapy cannot exert its antiangiogenic effect within a 3 weekly schedule. A possible explanation is the secondary recovery of MVD in response to immediate cytotoxic and antiangiogenic effects of taxane-based chemotherapy. If confirmed prospectively, these findings favor shorter treatment intervals of taxane-based chemotherapy to counteract proangiogenic recovery.

\section{Competing interests}

Walther Kuhn (Principal Investigator PRIMOVAR trial): Research Funding (SanofiAventis). All other authors indicated no potential conflict of interest.

\section{Authors' contributions}

MP designed research, acquired, analyzed data and drafted the manuscript. CR provided clinical and scientific support, performed surgical interventions, reviewed the manuscript. NF was responsible for the histopathological revision of the patient's samples and for analyzing immunohistochemical staining. MM acquisition and analysis of clinical and histopathological data, collected samples, coordinated staining. TH performed the statistical analysis. MW provided clinical and scientific support, performed surgical interventions, collected follow-up data. KK provided clinical and scientific support, applied chemotherapies within the PRIMOVAR trial. RB, Head of the Institute for Pathology, reviewed the manuscript. WK, Head of the Dept. of Obstetrics and Gynecology, Principle investigator of the PRIMOVAR trial, made a major financial, clinical and critical contribution to this work. MB co-designed and supervised the study, assisted in the writing of the manuscript.

All authors read and approved the final manuscript.

Presented in part at the ESGO European Meeting, Belgrade 2009

\section{Acknowledgements}

We thank Christiane Esch for technical assistance with immunohistochemistry. This is a single institution analysis of clinical data collected within a multicenter phase 2 trial, PRIMOVAR, ClinicalTrials.gov Identifier: .NCT00551577, sponsored by Sanofi-Aventis Deutschland GmbH

\section{Author Details}

'Department of Gynecology and Obstetrics, Center for Integrated Oncology, Bonn University Medical Center, Germany, 2Institute of Pathology, Center for Integrated Oncology, Bonn University Medical Center, Germany, 3Institute for Medical Biometry, Informatics, and Epidemiology, University of Bonn, Germany and ${ }^{4}$ Zentrale Klinische Forschung, University Freiburg, Germany

Received: 18 September 2009 Accepted: 13 April 2010

Published: 13 April 2010

\section{References}

1. Heintz AP, Odicino F, Maisonneuve P, Quinn MA, Benedet JL, Creasman WT, Ngan HY, Pecorelli S, Beller U: Carcinoma of the ovary. FIGO 6th Annual Report on the Results of Treatment in Gynecological Cancer. Int J Gynaecol Obstet 2006, 95(Suppl 1):S161-192.

2. Kuhn W, Rutke S, Spathe K, Schmalfeldt B, Florack G, von Hundelshausen B, Pachyn D, Ulm K, Graeff H: Neoadjuvant chemotherapy followed by tumor debulking prolongs survival for patients with poor prognosis in International Federation of Gynecology and Obstetrics Stage IIIC ovarian carcinoma. Cancer 2001, 92(10):2585-2591.

3. Park TW, Kuhn WC: Neoadjuvant chemotherapy in ovarian cancer. Expert Rev Anticancer Ther 2004, 4(4):639-647.

4. Polcher M, Mahner S, Ortmann O, Hilfrich J, Diedrich K, Breitbach GP, Hoss C, Leutner C, Braun M, Mobus V, et al:: Neoadjuvant chemotherapy with carboplatin and docetaxel in advanced ovarian cancer - a prospective multicenter phase II trial (PRIMOVAR). Oncol Rep 2009, 22(3):605-613.

5. Vergote IB, Tropé CG, Amant F, Kristensen GB, Sardi JE: EORTC-GCG/NCICCTG Randomised Trial Comparing Primary Debulking Surgery With Neoadjuvant Chemotherapy in Stage IIIC-IV Ovarian, Fallopian Tube and Peritoneal Cancer (OVCA). 12th Biennial Meeting, International Gynecological Cancer Society (IGCS): 2008; Bangkok 2008.

6. Hanahan D, Weinberg RA: The hallmarks of cancer. Cell 2000 100(1):57-70.

7. Folkman J: Tumor angiogenesis: therapeutic implications. N Engl J Med 1971, 285(21):1182-1186.

8. Weidner $\mathrm{N}$ : Intratumor microvessel density as a prognostic factor in cancer. Am J Pathol 1995, 147(1):9-19.

9. Alvarez AA, Krigman HR, Whitaker RS, Dodge RK, Rodriguez GC: The prognostic significance of angiogenesis in epithelial ovarian carcinoma. Clin Cancer Res 1999, 5(3):587-591.

10. Gasparini G, Bonoldi E, Viale G, Verderio P, Boracchi P, Panizzoni GA, Radaelli U, Di Bacco A, Guglielmi RB, Bevilacqua P: Prognostic and predictive value of tumour angiogenesis in ovarian carcinomas. Int $J$ Cancer 1996, 69(3):205-211.

11. Labiche A, Elie N, Herlin P, Denoux Y, Crouet H, Heutte N, Joly F, Heron JF, Gauduchon P, Henry-Amar M: Prognostic significance of tumour vascularisation on survival of patients with advanced ovarian carcinoma. Histol Histopathol 2009, 24(4):425-435.

12. Raspollini MR, Amunni G, Villanucci A, Baroni G, Boddi V, Taddei GL: Prognostic significance of microvessel density and vascular endothelial growth factor expression in advanced ovarian serous carcinoma. Int J Gynecol Cancer 2004, 14(5):815-823.

13. Rossochacka-Rostalska B, Gisterek IJ, Suder E, Szelachowska JK, Matkowski RA, Lacko A, Kornafel JA: [Prognostic significance of microvessel density in ovarian cancer]. Wiad Lek 2007, 60(3-4):129-137.

14. Rubatt JM, Darcy KM, Hutson A, Bean SM, Havrilesky LJ, Grace LA, Berchuck A, Secord AA: Independent prognostic relevance of microvessel density in advanced epithelial ovarian cancer and associations between CD31, CD105, p53 status, and angiogenic marker expression: A Gynecologic Oncology Group study. Gynecol Oncol 2009, 112(3):469-474.

15. Gadducci A, Ferrero A, Cosio S, Zola P, Viacava P, Dompe D, Fanelli G, Ravarino N, Motta M, Cristofani R, et al:: Intratumoral microvessel density in advanced epithelial ovarian cancer and its use as a prognostic variable. Anticancer Res 2006, 26(5B):3925-3932.

16. Obermair A, Wasicky R, Kaider A, Preyer O, Losch A, Leodolter S, Kolbl H: Prognostic significance of tumor angiogenesis in epithelial ovarian cancer. Cancer Lett 1999, 138(1-2):175-182. 
17. Ogawa S, Kaku T, Kobayashi H, Hirakawa T, Ohishi Y, Kinukawa N, Nakano $\mathrm{H}$ : Prognostic significance of microvessel density, vascular cuffing and vascular endothelial growth factor expression in ovarian carcinoma: a special review for clear cell adenocarcinoma. Cancer Lett 2002, 176(1):111-118

18. Newman PJ: The role of PECAM-1 in vascular cell biology. Ann N Y Acad Sci 1994, 714:165-174

19. Fonsatti E, Altomonte M, Nicotra MR, Natali PG, Maio M: Endoglin (CD105): a powerful therapeutic target on tumor-associated angiogenetic blood vessels. Oncogene 2003, 22(42):6557-6563.

20. Krause DS, Fackler MJ, Civin Cl, May WS: CD34: structure, biology, and clinical utility. Blood 1996, 87(1):1-13.

21. Kahn HJ, Marks A: A new monoclonal antibody, D2-40, for detection of lymphatic invasion in primary tumors. Lab Invest 2002, 82(9):1255-1257.

22. Miller KD, Sweeney CJ, Sledge GW Jr: Redefining the target: chemotherapeutics as antiangiogenics. J Clin Oncol 2001, 19(4):1195-1206.

23. Pölcher M, Mahner S, Ortmann O, Hilfrich J, Diedrich K: Neoadjuvant Chemotherapy With Carboplatin and Docetaxel in Advanced Ovarian Cancer - a Prospective Multicenter Phase 2 Trial (PRIMOVAR). Oncol Rep 2009, 22:605-613.

24. Weidner N: Current pathologic methods for measuring intratumoral microvessel density within breast carcinoma and other solid tumors. Breast Cancer Res Treat 1995, 36(2):169-180.

25. Klauber N, Parangi S, Flynn E, Hamel E, D'Amato RJ: Inhibition of angiogenesis and breast cancer in mice by the microtubule inhibitors 2-methoxyestradiol and taxol. Cancer Res 1997, 57(1):81-86.

26. Hotchkiss KA, Ashton AW, Mahmood R, Russell RG, Sparano JA, Schwartz EL: Inhibition of endothelial cell function in vitro and angiogenesis in vivo by docetaxel (Taxotere): association with impaired repositioning of the microtubule organizing center. Mol Cancer Ther 2002, 1(13):1191-1200.

27. Sweeney CJ, Miller KD, Sissons SE, Nozaki S, Heilman DK, Shen J, Sledge GW Jr: The antiangiogenic property of docetaxel is synergistic with a recombinant humanized monoclonal antibody against vascular endothelial growth factor or 2-methoxyestradiol but antagonized by endothelial growth factors. Cancer Res 2001, 61(8):3369-3372.

28. Grant DS, Williams TL, Zahaczewsky M, Dicker AP: Comparison of antiangiogenic activities using paclitaxel (taxol) and docetaxel (taxotere). Int J Cancer 2003, 104(1):121-129.

29. Rudlowski C, Pickart AK, Fuhljahn C, Friepoertner T, Schlehe B, Biesterfeld S, Schroeder W: Prognostic significance of vascular endothelial growth factor expression in ovarian cancer patients: a long-term follow-up. Int J Gynecol Cancer 2006, 16(Suppl 1):183-189.

30. Dome B, Timar J, Ladanyi A, Paku S, Renyi-Vamos F, Klepetko W, Lang G, Dome P, Bogos K, Tovari J: Circulating endothelial cells, bone marrowderived endothelial progenitor cells and proangiogenic hematopoietic cells in cancer: From biology to therapy. Crit Rev Oncol Hematol 2009, 69(2):108-124

31. Asahara T, Kawamoto A: Endothelial progenitor cells for postnatal vasculogenesis. Am J Physiol Cell Physiol 2004, 287(3):C572-579.

32. Shaked Y, Henke E, Roodhart JM, Mancuso P, Langenberg MH, Colleoni M, Daenen LG, Man S, Xu P, Emmenegger U, et al:: Rapid chemotherapyinduced acute endothelial progenitor cell mobilization: implications for antiangiogenic drugs as chemosensitizing agents. Cancer Cell 2008, 14(3):263-273

33. Bertolini F, Paul S, Mancuso P, Monestiroli S, Gobbi A, Shaked Y, Kerbel RS: Maximum tolerable dose and low-dose metronomic chemotherapy have opposite effects on the mobilization and viability of circulating endothelial progenitor cells. Cancer Res 2003, 63(15):4342-4346.

34. Kerbel RS, Kamen BA: The anti-angiogenic basis of metronomic chemotherapy. Nat Rev Cancer 2004, 4(6):423-436

35. Garcia AA, Hirte H, Fleming G, Yang D, Tsao-Wei DD, Roman L, Groshen S, Swenson S, Markland F, Gandara D, et al:: Phase II clinical trial of bevacizumab and low-dose metronomic oral cyclophosphamide in recurrent ovarian cancer: a trial of the California, Chicago, and Princess Margaret Hospital phase II consortia. J Clin Oncol 2008, 26(1):76-82.

36. Kamat AA, Kim TJ, Landen CN Jr, Lu C, Han LY, Lin YG, Merritt WM, Thaker $\mathrm{PH}$, Gershenson DM, Bischoff FZ, et al:: Metronomic chemotherapy enhances the efficacy of antivascular therapy in ovarian cancer. Cancer Res 2007, 67(1):281-288.

37. Schirner M: Antiangiogenic chemotherapeutic agents. Cancer Metastasis Rev 2000, 19(1-2):67-73

38. Bertolini F, Shaked Y, Mancuso P, Kerbel RS: The multifaceted circulating endothelial cell in cancer: towards marker and target identification. Nat Rev Cancer 2006, 6(11):835-845.

39. Giannakakou P, Robey R, Fojo T, Blagosklonny MV: Low concentrations of paclitaxel induce cell type-dependent p53, p21 and G1/G2 arrest instead of mitotic arrest: molecular determinants of paclitaxel-induced cytotoxicity. Oncogene 2001, 20(29):3806-3813.

40. Pasquier E, Honore S, Pourroy B, Jordan MA, Lehmann M, Briand C, Braguer $D$ : Antiangiogenic concentrations of paclitaxel induce an increase in microtubule dynamics in endothelial cells but not in cancer cells. Cancer Res 2005, 65(6):2433-2440.

41. Katsumata N, Yasuda M, Takahashi F, Isonishi S, Jobo T, Aoki D, Tsuda H, Sugiyama T, Kodama S, Kimura E, et al: Dose-dense paclitaxel once a week in combination with carboplatin every 3 weeks for advanced ovarian cancer: a phase 3, open-label, randomised controlled trial. Lancet 2009, 374(9698):1331-1338.

42. Bolis G, Scarfone G, Polverino G, Raspagliesi F, Tateo S, Richiardi G, Melpignano M, Franchi M, Mangili G, Presti M, et al:: Paclitaxel 175 or 225 mg per meters squared with carboplatin in advanced ovarian cancer: a randomized trial. J Clin Oncol 2004, 22(4):686-690.

43. Muggia FM, Braly PS, Brady MF, Sutton G, Niemann TH, Lentz SL, Alvarez RD, Kucera PR, Small JM: Phase III randomized study of cisplatin versus paclitaxel versus cisplatin and paclitaxel in patients with suboptimal stage III or IV ovarian cancer: a gynecologic oncology group study. J Clin Oncol 2000, 18(1):106-115.

44. Omura GA, Brady MF, Look KY, Averette HE, Delmore JE, Long HJ, Wadler S, Spiegel G, Arbuck SG: Phase III trial of paclitaxel at two dose levels, the higher dose accompanied by filgrastim at two dose levels in platinumpretreated epithelial ovarian cancer: an intergroup study. J Clin Oncol 2003, 21(15):2843-2848

45. Kim JJ, Tannock IF: Repopulation of cancer cells during therapy: an important cause of treatment failure. Nat Rev Cancer 2005, 5(7):516-525.

46. Burger RA, Sill MW, Monk BJ, Greer BE, Sorosky Jl: Phase II trial of bevacizumab in persistent or recurrent epithelial ovarian cancer or primary peritoneal cancer: a Gynecologic Oncology Group Study. Clin Oncol 2007, 25(33):5165-5171.

47. Cannistra SA, Matulonis UA, Penson RT, Hambleton J, Dupont J, Mackey H, Douglas J, Burger RA, Armstrong D, Wenham R, et al.: Phase II study of bevacizumab in patients with platinum-resistant ovarian cancer or peritoneal serous cancer. J Clin Oncol 2007, 25(33):5180-5186.

48. Ebos JM, Lee CR, Cruz-Munoz W, Bjarnason GA, Christensen JG, Kerbel RS: Accelerated metastasis after short-term treatment with a potent inhibitor of tumor angiogenesis. Cancer Cell 2009, 15(3):232-239.

49. Paez-Ribes M, Allen E, Hudock J, Takeda T, Okuyama H, Vinals F, Inoue M, Bergers $G$, Hanahan D, Casanovas O: Antiangiogenic therapy elicits malignant progression of tumors to increased local invasion and distant metastasis. Cancer Cell 2009, 15(3):220-231.

\section{Pre-publication history}

The pre-publication history for this paper can be accessed here: http://www.biomedcentral.com/1471-2407/10/137/prepub

doi: 10.1186/1471-2407-10-137

Cite this article as: Pölcher et al., In vivo intratumor angiogenic treatment effects during taxane-based neoadjuvant chemotherapy of ovarian cancer BMC Cancer 2010, 10:137 